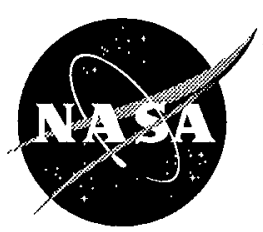

\title{
Wave Augmented Diffusers for Centrifugal Compressors
}

Daniel E. Paxson

Lewis Research Center, Cleveland, Ohio

Gary J. Skoch

U.S. Army Research Laboratory, Cleveland, Ohio

Prepared for the

34th Joint Propulsion Conference

cosponsored by AIAA, ASME, SAE, and ASEE

Cleveland, Ohio, July 12-15, 1998

National Aeronautics and

Space Administration

Lewis Research Center 
Available from

NASA Center for Aerospace Information 7121 Standard Drive

Hanover, MD 21076

Price Code: A03
National Technical Information Service 5287 Port Royal Road Springfield, VA 22100 


\title{
WAVE AUGMENTED DIFFUSERS FOR CENTRIFUGAL COMPRESSORS
}

\author{
Daniel E. Paxson ${ }^{\dagger}$ \\ NASA Lewis Research Center \\ Cleveland, Ohio, USA \\ Gary J. Skoch \\ U.S. Army Research Laboratory \\ NASA Lewis Research Center \\ Cleveland, Ohio, USA
}

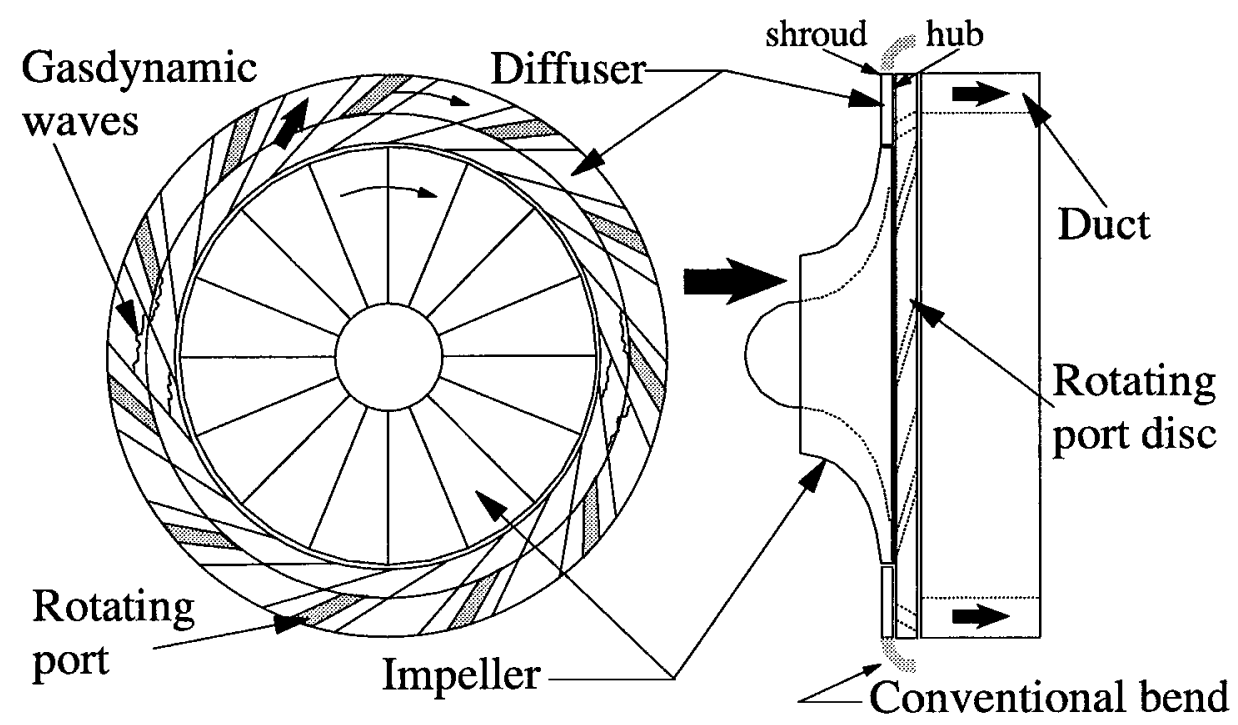

Figure 1 Wave Augmented Diffuser Schematic

\section{Abstract}

A conceptual device is introduced which would utilize unsteady wave motion to slow and turn flows in the diffuser section of a centrifugal compressor. The envisioned device would substantially reduce the size of conventional centrifugal diffusers by eliminating the relatively large ninety degree bend needed to turn the flow from the radial/tangential to the axial direction. The bend would be replaced by a wall and the flow would instead exit through a series of rotating ports located on a disk, adjacent to the diffuser hub, and fixed to the impeller shaft. The ports would generate both expansion and compression waves which would rapidly transition from the hub/shroud (axial) direction to the radial/tangential direction. The waves would in turn induce radial/tangential and axial flow. This paper

\footnotetext{
${ }^{\dagger}$ Member AIAA

Copyright (c) 1998 by the American Institute of Aeronautics and Astronautics, Inc. No copyright is asserted in the United States under Title 17, U.S. Code. The U.S. Government has a royalty-free license to exercise all rights under the copyright claimed herein for Governmental Purposes. All other rights arc reserved by the copyright owner.
}

presents a detailed description of the device. Simplified cycle analysis and performance results are presented which were obtained using a time accurate, quasi-onedimensional CFD code with models for turning, port flow conditions, and losses due to wall shear stress. The results indicate that a periodic wave system can be established which yields diffuser performance comparable to a conventional diffuser. Discussion concerning feasibility, accuracy, and integration follow.

\section{Introduction}

Pressure exchange devices, which transfer energy within a fluid system by means of unsteady gasdynamic waves have been proposed or constructed to perform a variety of thermodynamic cycles ${ }^{1-9}$. Sometimes called wave rotors, their potential applications include topping cycles for gas turbines, turbocharging for automobiles, ejectors (e.g. pressure equalizers), and pressure dividers. ${ }^{6}$ For topping and turbocharging cycles, where the unsteady waves replace conventional rotating blades, wave rotors offer the potential advantages of 


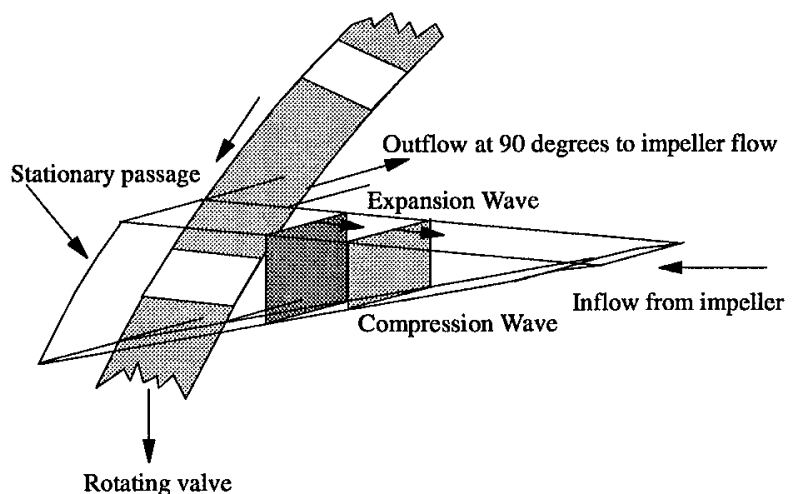

Figure 2 Wave Augmented Diffuser Section

self-cooling, low rotational speed, and relative simplicity. For ejector cycles, unsteady waves replace the dissipative viscous work transfer mechanisms of their steady flow counterpart. The result is a substantial improvement in measured effectiveness. The simplicity of the steady ejectors is lost however, and it must be assessed for a particular application whether the enhancement benefit outweighs the complexity detriment. ${ }^{10}$

This paper presents an investigation to ascertain whether pressure exchangers can be used to replace or augment other fluidic devices. In particular, the potential use of a pressure-exchange based diffuser for centrifugal compressors is examined. Conventional centrifugal diffusers are long, adding additional diameter to the overall engine layout due in part to the 90 degree turn which transitions the flow from the radial/tangential to the axial direction. The pressureexchanger, or wave augmented diffuser may offer substantial reduction in overall size by utilizing gasdynamic waves to temporarily bring the flow to rest and pressurize it before it takes the turn. The device, shown schematically in Fig. 1, would be mechanically complex compared to a conventional steady diffuser; however, if space is at a premium, the benefit may be substantial. The wave augmented diffuser concept will be presented. A quasi-one-dimensional CFD based simulation will then be described which has been used to analyze the concept. Simulation results for a particular design will then be presented, and the implications discussed.

\section{The Wave Augmented Diffuser Concept}

The proposed operation of the wave augmented diffuser is illustrated in Fig. 2 which shows an enlarged diffuser passage from Fig. 1. In principle, the flow in the section would be brought to rest by a compression wave initiated by passing of the rotating port (e.g. closing the rotary valve) on the hub wall. Although shown as a plane wave in the figure, it is noted that the actual

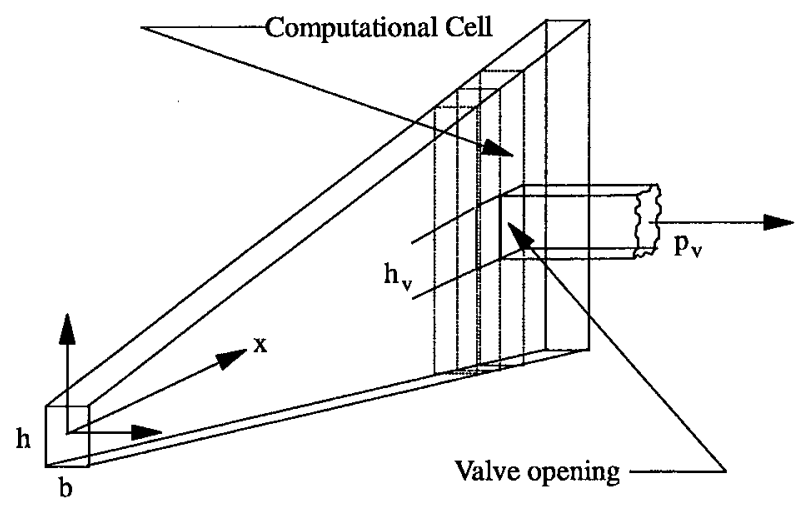

Figure 3 Envisioned Q-1-D Computational Domain

compression wave would initially be highly three dimensional. Since it is initiated at the hub wall, and since the valve occupies less than the full pitch of the passage, information would propagate and reflect several times in both the axial and circumferential directions before anything approaching a plane wave formed. After the wave has traveled part way down the section toward the inlet, the rotating valve would open, initiating an expansion wave which would travel faster than, and eventually overtake the compression wave. During this period flow would then exit the diffuser section through the valve while the expansion wave caught and canceled the compression wave before it reached the diffuser section entrance. At this point the rotary valve would close and another cycle would begin.

The potential advantage of the concept lies in the notion that the majority of fluid which must navigate the 90 degree turn during a cycle has been brought to rest at high pressure. This leads to a low-loss turning process.

Simulation and Analysis

Accurate simulation of a device like that shown in Fig. 1 requires a time-accurate, viscous, three-dimensional CFD code. Although such codes are available, they are not practical for preliminary analysis due to the large time requirements necessary to obtain a solution. For preliminary analysis a highly simplified model was developed based on the following assumptions:

1. The diffuser section may be replaced by a simple symmetric wedge as shown in Fig. 3.

2. The dominant wave phenomena occur along the $\mathrm{x}$-axis (see Fig. 3).

3. All other flow aspects can be modeled.

The wave augmented diffuser may thus be simulated using a quasi-one-dimensional, perfect gas flow solver with additional source terms to account for viscous 
effects and flows from the passage normal to the mean flow direction. Such a code has been developed by the authors and described in detail in the literature. ${ }^{11}$

For reference, the numerically integrated governing equations may be written in non-dimensional form as:

$$
\frac{\partial \overline{\mathrm{w}}}{\partial \tau}+\frac{\partial \overline{\mathrm{F}}(\overline{\mathrm{w}})}{\partial \mathrm{x}^{\prime}}=\overline{\mathrm{S}}(\overline{\mathrm{w}})
$$

where

$$
\bar{w}=\left[\begin{array}{c}
\rho^{\prime} h^{\prime} \\
\rho^{\prime} u^{\prime} h^{\prime} \\
\frac{p^{\prime} h^{\prime}}{\gamma(\gamma-1)}+\rho^{\prime} h^{\prime} u^{\prime 2}
\end{array}\right]
$$

and

$$
\overline{\mathrm{F}}=\left[\begin{array}{c}
\rho^{\prime} u^{\prime} h^{\prime} \\
\frac{p^{\prime} h^{\prime}}{\gamma}+\rho^{\prime} h^{\prime} u^{\prime 2} \\
\frac{p^{\prime} h^{\prime} u^{\prime}}{(\gamma-1)}+\frac{\rho^{\prime} h^{\prime} u^{3^{3}}}{2}
\end{array}\right]
$$

The distance, $x^{\prime}$ has been normalized by the passage length, $\mathrm{L}$. The time, $\tau$ has been normalized by the characteristic wave transit time, $L / a^{*}$, where $\mathrm{a}^{*}$ is the reference speed of sound. The pressure, $\mathrm{p}^{\prime}$ and density, $\rho^{\prime}$ have been normalized by their respective reference values and the axial velocity, u' has been normalized by $a^{*}$. The passage height, $h^{\prime}$ has been normalized by the reference value $h^{*}$. The ratio of specific heats is denoted by $\gamma$.

The source term $\overline{\mathrm{S}}(\overline{\mathrm{w}})$ contains expressions for the effects of wall friction and for flow through the rotary valve. It is written as

$$
\left[\begin{array}{c}
s^{1} \\
s^{2} \\
s^{3}
\end{array}\right]=\left[\begin{array}{r}
-C_{D} \sigma_{1} \alpha h^{\prime}\left(\frac{L}{b}\right) \sqrt{p^{\prime} \rho^{\prime} f}\left(\frac{p_{v}^{\prime}}{p^{\prime}}\right) \\
u^{\prime} s_{1}+\frac{p^{\prime}}{\gamma} \frac{d h^{\prime}}{d x^{\prime}}-\sigma_{2} u^{\prime} \mid \rho^{\prime} u^{\prime} \cdot 75 h^{\prime}\left(\frac{D_{h}^{*}}{D_{h}}\right) \\
s_{1}\left(\frac{p^{\prime}}{\rho^{\prime}(\gamma-1)}+\frac{u^{\prime 2}}{2}\right)
\end{array}\right]
$$

where $\alpha$ is the ratio of $h_{v}$ to $h$ (see Fig. 3), $b$ is the constant passage width, $D_{h}$ is the hydraulic diameter, $C_{D}$, and $\sigma_{1}$ and $\sigma_{2}$ are fluid and/or geometric constants.
The function $f\left(\frac{p_{v}^{\prime}}{p^{\prime}}\right)$ is St. Venant's orifice equation. ${ }^{12}$ The back pressure $p_{\mathrm{v}}^{\prime}$ is specified. It is assumed in this formulation that flow from the diffuser section carries all of the $\mathrm{x}$-direction momentum with it.

\section{Numerical Integration}

The scheme used to numerically integrate Eqn. (1) has been detailed in Ref. 11. It is an upwind, LaxWendroff scheme which utilizes Roe's approximate Riemann solver ${ }^{13}$ to obtain flux estimates at the numerical cell faces. The source vector, Eqn. (4) is dealt with in a consistent, second order fashion, with the spatial height derivative estimated using central differencing. For all of the results to be shown, 100 numerical cells were used with a corresponding nondimensional time step of $\Delta \tau=0.003$.

\section{Turning Loss Estimate}

In order to estimate the losses encountered in turning the flow at a sharp right angle to exit the diffuser passage, the following model was used. At any instant of time the properties in the rotary valve are obtained using a constant pressure mixing calculation over all of the numerical cells for which the mass flow source term is non-zero, i.e.

$$
\begin{aligned}
& \overline{\mathbf{p}}_{\mathrm{v}}^{\prime}=\mathrm{p}_{\mathrm{v}}^{\prime} \\
& \overline{\mathrm{u}}_{\mathrm{v}}^{\prime}=\frac{\sqrt{\left(\frac{\mathrm{p}_{\mathrm{v}}^{\prime}}{\gamma-1}\right)^{2}+2 \mathrm{~m}_{\mathrm{f}} \mathrm{e}_{\mathrm{f}}-\frac{\mathrm{p}_{\mathrm{v}}^{\prime}}{\gamma-1}}}{\mathrm{~m}_{\mathrm{f}}} \\
& \bar{\rho}_{\mathrm{v}}^{\prime}=\frac{\mathrm{m}_{\mathrm{f}}}{\overline{\mathrm{u}}_{\mathrm{v}}^{\prime}}
\end{aligned}
$$

where

$$
\mathrm{m}_{\mathrm{f}}=\frac{\sum_{\mathrm{i}=\mathrm{K}_{1}}^{\mathrm{K}_{2}} \mathrm{~s}_{\mathrm{i}}^{1}\left(\frac{\mathrm{b}}{\mathrm{L}}\right)}{\alpha \sum_{\mathrm{i}=\mathrm{K}_{1}}^{\mathrm{K}_{2}} \mathrm{~h}_{\mathrm{i}}^{\prime}}
$$

The instantaneous, mixed state (Eqn. 5) is then integrated over the entire time that the valve is opened and used to obtain a mixed time averaged state via 


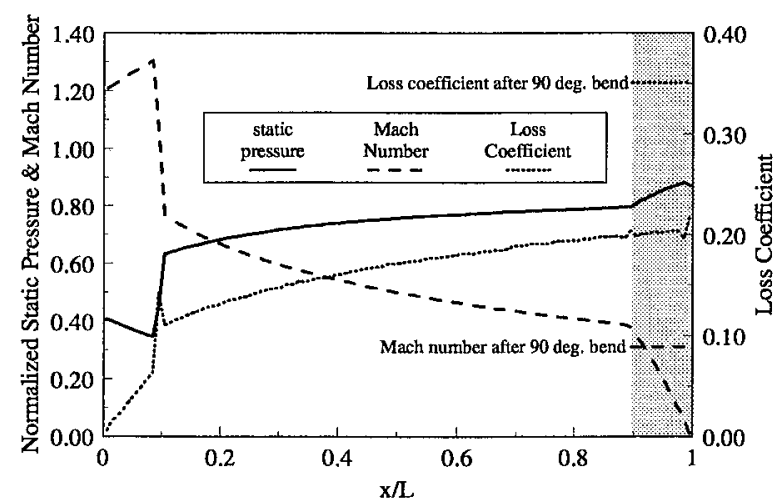

Figure 4 Distribution of Baseline Diffuser Flow Properties

$$
\begin{aligned}
& \overline{\overline{\mathrm{p}}}_{\mathrm{v}}^{\prime}=\frac{\gamma}{\mathrm{J}}\left(\overline{\mathrm{q}}_{\mathrm{f}}-\overline{\mathrm{m}}_{\mathrm{f}} \overline{\overline{\mathrm{u}}}_{\mathrm{v}}^{\prime}\right) \\
& \overline{\overline{\mathrm{u}}}_{\mathrm{v}}^{\prime}=\frac{\gamma \overline{\mathrm{q}}_{\mathrm{f}}-\sqrt{\left(\gamma \overline{\mathrm{q}}_{\mathrm{f}}\right)^{2}+2(\gamma+1) \overline{\mathrm{m}}_{\mathrm{f}} \overline{\mathrm{e}}_{\mathrm{f}}}}{(\gamma+1) \overline{\mathrm{m}}_{\mathrm{f}}} \\
& \overline{\bar{\rho}}_{\mathrm{v}}^{\prime}=\frac{\overline{\mathrm{m}}_{\mathrm{f}}}{\overline{\overline{\mathrm{u}}}_{\mathrm{v}}^{\prime}}
\end{aligned}
$$

$$
\begin{aligned}
& \overline{\mathrm{m}}_{\mathrm{f}}=\sum_{1}^{\mathrm{J}} \mathrm{m}_{\mathrm{f}} \\
& \overline{\mathrm{q}}_{\mathrm{f}}=\sum_{1}^{\mathrm{J}} \frac{\overline{\mathrm{p}}_{\mathrm{v}}^{\prime}}{\gamma}+\mathrm{m}_{\mathrm{f}} \overline{\mathrm{u}}_{\mathrm{v}}^{\prime} \\
& \overline{\mathrm{e}}_{\mathrm{f}}=\sum_{1}^{\mathrm{J}} \overline{\mathrm{u}}_{\mathrm{v}}^{\prime}\left(\overline{\mathrm{p}}_{\mathrm{v}}^{\prime}+\frac{\gamma-1}{2} \mathrm{~m}_{\mathrm{f}} \overline{\mathrm{u}}_{\mathrm{v}}^{\prime}\right)
\end{aligned}
$$

\begin{tabular}{cc} 
Discharge Coefficient, $\mathrm{C}_{\mathrm{D}}$ & 0.800 \\
Friction Coefficient $\sigma_{2}$ & 0.170 \\
Valve Back Pressure, $\mathrm{p}_{\mathrm{v}}^{\prime}$ & 0.742 \\
\hline
\end{tabular}

steps during which the valve is open. This modeling of the turning loss represents a very conservative estimate in that both of the mixing calculations in Eqnis. 5-6 and $7-8$ produce entropy and the flow is assumed at the outset to lose all of the $x$-direction (in Fig. 3) momentum as it enters the rotary valve.

\section{Baseline Steady Diffuser}

Although a high degree of accuracy is not expected from the simulation, it seems reasonable to test it, and the wave augmented diffusion concept against a representative baseline steady diffuser. The diffuser chosen is similar to that for an 8 to 1 pressure ratio compressor tested at NASA Lewis Research Center. ${ }^{14}$ For the simplified geometry shown in Fig. 3, the relevant target performance parameters are shown in Table 1 . It was arbitrarily assumed that of the total loss coefficient shown in Table 1,67\% was due to viscous loss in the passage, and $33 \%$ was due to losses associated with the 90 degree turn. For simulation of the baseline diffuser, the rotary valve was held in the opened position. The lengthwise extent of the valve, $\mathrm{x}_{\mathrm{v}}^{\prime}$ was $10 \%$ of the total passage length. Values of passage slope $\frac{\mathrm{dh}^{\prime}}{\mathrm{dx}^{\prime}}$ (assumed constant), valve height $\mathrm{h}_{\mathrm{v}}^{\prime}$, friction coefficient $\sigma_{2}$, discharge coefficient, $C_{D}$ and back pressure $\mathrm{p}_{\mathrm{v}}^{\prime}$ were adjusted to meet as closely as possible the requirements of Table 1 . The values for these parameters are listed in Table 2.

\section{Table 1 Baseline Diffuser Target Performance} Parameters

\begin{tabular}{cc}
\hline Inlet Mach Number & 1.20 \\
Exit Mach Number & 0.40 \\
Mach Number After $90^{\circ}$ Turn & 0.30 \\
Target Loss Coefficient, $\mathrm{f}_{\mathrm{L}} \equiv \frac{\mathrm{P}_{\text {in }}-\mathrm{P}_{\mathrm{v}}}{\mathrm{P}_{\text {in }}-\mathrm{p}_{\text {in }}}$ & 0.30 \\
Number of Passages & 22 \\
Non-dimensional Impeller Rotation Period & \\
$\tau_{\text {imp }} \equiv \frac{\mathrm{Ta} *}{\mathrm{~L}}$ & 7.30 \\
\hline \hline
\end{tabular}

Table 2 Baseline Diffuser Simulation Parameters for Eqn. 4

\begin{tabular}{lc}
\hline $\mathrm{\alpha}=\mathrm{h}_{\mathrm{v}} / \mathrm{h}$ & 0.700 \\
$\mathrm{~b} / \mathrm{L}$ & .0588 \\
$\frac{\mathrm{dh}^{\prime}}{\mathrm{dx}^{\prime}}$ & 0.90 \\
Valve Extent, $\mathrm{x}_{\mathrm{v}}^{\prime}$ & 0.100 \\
Coefficient, $\mathrm{C}_{\mathrm{D}}$ & 0.800 \\
Coefficient $\sigma_{2}$ & 0.170 \\
Mack Pressure, $\mathrm{p}_{\mathrm{v}}^{\prime}$ & 0.742 \\
\hline
\end{tabular}

Computed Mach number, normalized static pressure, and total pressure loss coefficient profiles for this baseline diffuser are shown in Fig. 4. Also shown are the loss coefficient and Mach number after the 90 degree bend mixing calculation. It was not possible to match the Table 1 target total pressure loss coefficient parameter because the loss associated with the turn was too large. This is somewhat reassuring however, as it indicates that under the modeling simplifications described, a steady state diffuser and 90 degree turn of this design would perform poorly; which is obviously true.

\section{Unsteady Diffuser}

Many different configurations for the placement, and size of the rotating valve were been examined. All of the simulations utilized the same friction coefficient, $\sigma_{2}$, discharge coefficient, $C_{D}$ and passage geometry as the baseline diffuser. The timing (opening or closing) of the valve was restricted to be integer multiples of the 

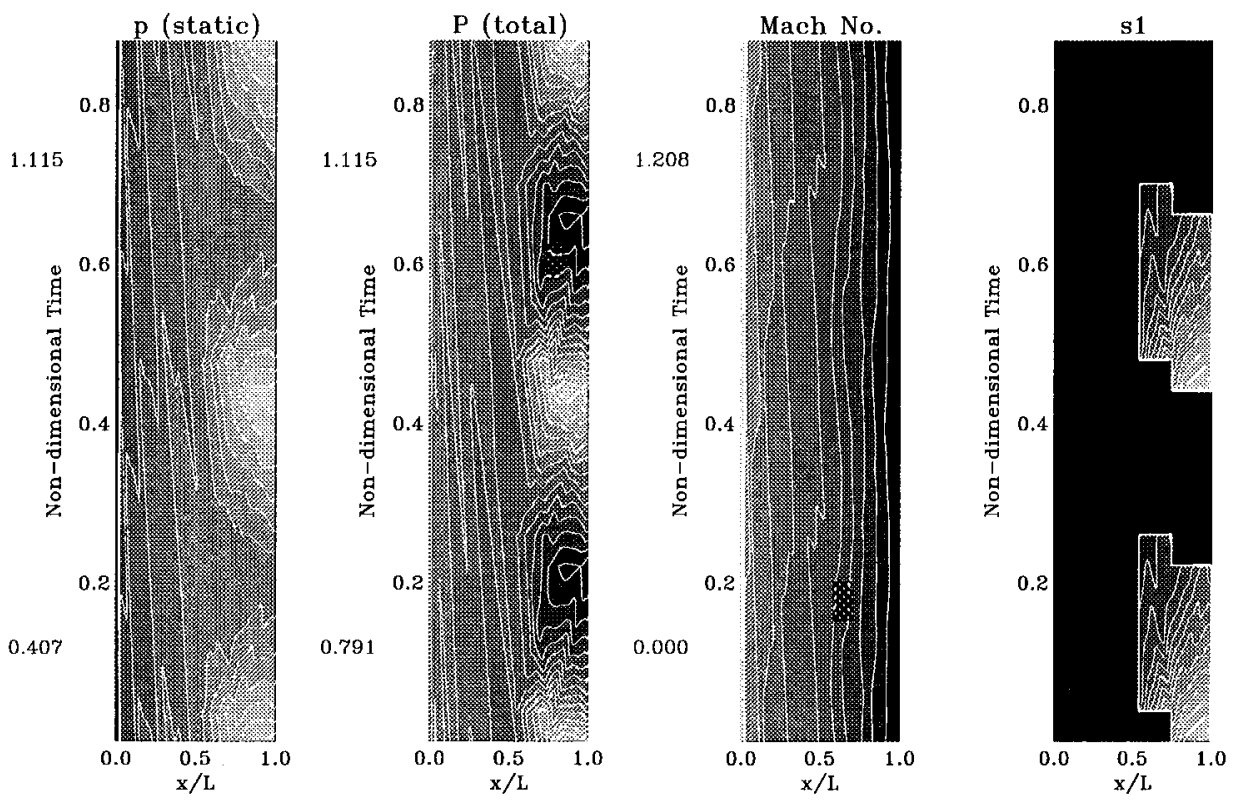

Figure 5 Property Contours for Two Cycles of the Wave Augmented Diffuser

impeller rotation period given in Table 1 divided by a typical number of diffuser passages (chosen as 44). Variable parameters were the valve height $h_{v}^{\prime}$, the back pressure $p_{v}^{\prime}$, the lengthwise extent of the valve, and the timing. The objective was to maintain the 1.2 inlet Mach number and 0.3 mass and time averaged rotary valve Mach number of the baseline case while maximizing the total pressure in the rotary valve.

The configuration which has yielded the best results to date is illustrated using the contour plots shown in Fig. 5. Other relevant parameters are listed in Table 3, the most important of which is the substantially reduced (0.35 to 0.3 ) loss coefficient.

Figure 5 shows computed contours of static pressure, total pressure, $s^{1}$ in Eqn. (4), and Mach number over two wave cycles. Darker shades indicate lower values of a quantity. The numbers next to each contour show the minimum and maximum of the plotted quantity observed during a cycle. The pressure values have been scaled by the diffuser inlet stagnation value. Unlike other pressure-exchange devices, the waves here are not particularly strong; however, they are not acoustic either. Note in particular that the stagnation pressure is $20 \%$ higher than the inlet value at some point in the cycle. It can be seen in the contour of $s^{1}$ that the rotary valve extends $47 \%$ of the passage length, with some slight phasing between the forward and aft portions. Thus, this configuration would appear very similar to Fig. 1.
Figure 6 shows the time-averaged (over one cycle) Mach number and loss coefficient distribution in the passage. It is interesting to note that this loss coefficient is lower than the baseline diffuser along nearly the entire length of the passage.

\section{Discussion}

Given the simplicity of the simulation and analysis, there are many aspects which can be debated. It should be kept in mind however, that the objective of the present work was simply to assess the plausibility of a concept, which appears to have potential. At the very least, the results thus presented warrant further investigation, perhaps with multidimensional CFD codes. Nevertheless, some comments regarding the concept and analysis are in order.

\section{Boundary Layer and Mixing Effects}

A major cause of stagnation pressure loss in typical diffuser passages comes from boundary layer separation and mixing. The present simulation achieves the equivalent loss through the friction term in Eqn 4. Obviously, such simplistic modeling cannot capture the effects which the unsteady wave diffuser flowfield will have on the boundary layer. Viewed another way, the time-averaged flow deceleration shown in Fig. 6 presumably could not be achieved within the specified geometry in a steady flow diffuser (e.g. the flow would separate considerably). There is no strong evidence one way or the other that it could be done in the unsteady flowfield, though that is assumed in the present simulation. In fact, the entire question of non-steady boundary layer and separation behavior is an open one. 


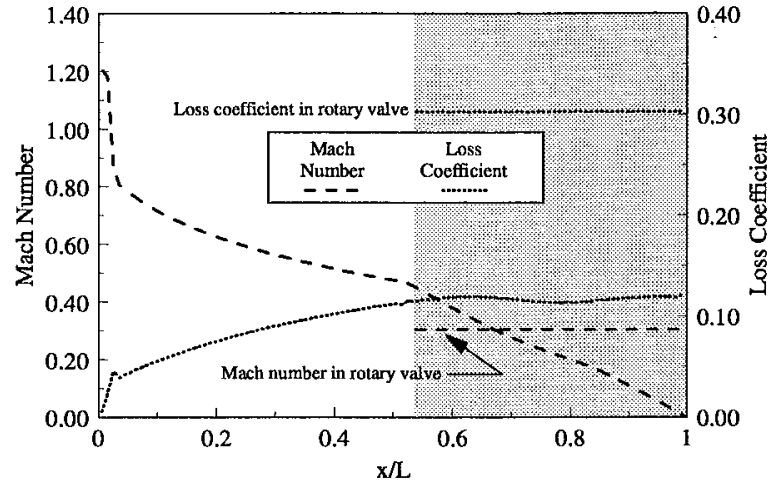

Figure 6 Distribution of Time Averaged Wave Augmented Diffuser Flow Properties

It is at least plausible however, that unsteadiness such as that envisioned for the wave augmented diffuser may forestall separation to some degree.

Integration

If the aerodynamic performance is indeed born out through more detailed analysis, the question of practical integration remains. The reduction in radius is a compelling benefit. The rotary valve however, while directly coupled to the impeller in concept, presents sealing and radial expansion difficulties, as well as increased disk friction due to the additional surface moving relative to the diffuser passages, which may offset the potential gains.

\section{Low Speed Application}

The results thus far presented pertain to a high speed centrifugal compressor diffuser. There is no reason however, that the concept could not be applied to a low speed machine. The traveling waves would undoubtedly lead to small pressure perturbations at the inlet to the diffuser due to the typical subsonic flow there; however, with careful design, this could be minimized. Investigations of this application are planned.

\section{Conclusions}

A new concept to reduce diffuser size in centrifugal compressors has been described. A numerical simulation has been developed with which to analyze it. Despite numerous simplifying assumptions, the simulation results indicate that the wave augmented diffuser is a viable concept which warrants further investigation.

\section{References}

1. Foa, J. V., Elements of Flight Propulsion, John Wiley and Sons, 1960.

2. Kentfield, J. A. C., Nonsteady One-Dimensional

Table 3 Wave Augmented Diffuser Simulation Parameters

$\alpha$

Non-Dimensional Cycle Time

$$
\tau_{\text {cyc }} \equiv \frac{\mathrm{T}_{\mathrm{cyc}} \mathrm{a}^{*}}{\mathrm{~L}}
$$

Lengthwise Valve Extent, $x_{v}^{\prime}$

Loss Coefficient, $f_{L} \equiv \frac{P_{\text {in }}-P_{v}}{P_{\text {in }}-p_{\text {in }}}$

Rotary Valve Back Pressure, $p_{v}^{\prime}$

Internal Compressible Flows: Theory and Application, Oxford University Press, 1993.

3. Azoury, P.H., Engineering Application of Unsteady Fluid Flow, Wiley and Sons, 1992.

4. Gyarmathy, George, "How Does the Comprex® Pressure-Wave Supercharger Work?," SAE paper \# 830234.

5. Taussig, R. T., "Energy Exchanger Performance and Power Cycle Evaluation-Experiments and Analysis," Final Report DOE/ER/01084--T1, 1980.

6. Kentfield, J. A. C., "An Examination of the Performance of Pressure Exchanger Equalizers and Dividers," $\mathrm{PhD}$ Thesis, U. of London, 1963 (also in Journal of Basic Engineering, September, 1969).

7. Klapproth, J. F, "Wave Engine Project," General Electric Quarterly Reports, 1960.

8. Weber, Helmut E., Shock Wave Engine Design, John Wiley, New York, 1995.

9. Shreeve, R. P. and Mathur, A., eds., "Proceedings of the 1985 ONR/NAVAIR Wave Rotor Research and Technology Workshop," NPS-67-85-008, May, 1985.

10. Roan, V. P. "An Ejector Performance Correlation Factor," AIAA paper 91-2545, June, 1991.

11. Paxson, D. E. and Lindau, J. W., "Numerical Assessment of Four-Port, Through-Flow Wave Rotor Cycles With Passage Height Variation," AIAA paper 97-3143, July, 1997, also NASA TM 107490

12. Egli, A., "The Leakage of Steam Through Labyrinth Seals," Transactions of the ASME, Vol. 57, 1935, pp. 115-122.

13. Roe, P. L., "Characteristic Based Schemes for the Euler Equations," Annual Review of Fluid Mechanics, 1986, Vol. 18, pp. 337-65.

14. Skoch, G. J., Moore, R. D., "Performance of Two 10-lb/sec Centrifugal Compressors With Different Blade and Shroud Thicknesses Operating Over a Range of Reynolds Numbers,"AIAA paper 871745, July 1987. 
Public reporting burden for this collection of information is estimated to average 1 hour per response, including the time for reviewing instructions, searching existing data sources, gathering and maintaining the data needed, and completing and reviewing the collection of information. Send comments regarding this burden estimate or any other aspect of this collection of information, including suggestions for reducing this burden, to Washington Headquarters Services, Directorate for Information Operations and Reports, 1215 Jefferson Davis Highway, Suite 1204, Arlington, VA 22202-4302, and to the Office of Management and Budget, Paperwork Reduction Project (0704-0188), Washington, DC 20503.

\begin{tabular}{|l|c|c|}
\hline 1. AGENCY USE ONLY (Leave blank) & $\begin{array}{c}\text { 2. REPORT DATE } \\
\text { July } 1998\end{array}$ & $\begin{array}{r}\text { 3. REPORT TYPE AND DATES COVERED } \\
\text { Technical Memorandum }\end{array}$
\end{tabular}

\section{TITLE AND SUBTITLE}

Wave Augmented Diffusers for Centrifugal Compressors

\section{AUTHOR(S)}

Daniel E. Paxson and Gary J. Skoch

\section{PERFORMING ORGANIZATION NAME(S) AND ADDRESS(ES)}

National Aeronautics and Space Administration

Lewis Research Center

Cleveland, Ohio 44135-3191

9. SPONSORING/MONITORING AGENCY NAME(S) AND ADDRESS(ES)

National Aeronautics and Space Administration

Washington, DC 20546-0001

\section{FUNDING NUMBERS}

WU-523-26-33-00

8. PERFORMING ORGANIZATION

REPORT NUMBER

$\mathrm{E}-11253$

10. SPONSORING/MONITORING AGENCY REPORT NUMBER

NASA TM-1998-208480

AIAA-98-3401

\section{SUPPLEMENTARY NOTES}

Prepared for the 34th Joint Propulsion Conference cosponsored by AIAA, ASME, SAE, and ASEE, Cleveland, Ohio, July 12-15, 1998. Daniel E. Paxson, NASA Lewis Research Center and Gary J. Skoch, U.S. Army Research Laboratory, Lewis Research Center, Cleveland, Ohio 44135. Responsible person, Daniel E. Paxson, organization code 5530, (216) 433-8334.

12a. DISTRIBUTION/AVAILABILITY STATEMENT 12b. DISTRIBUTION CODE

Unclassified - Unlimited

Subject Category: 07

Distribution: Nonstandard

This publication is available from the NASA Center for AeroSpace Information, (301) 621-0390.

13. ABSTRACT (Maximum 200 words)

A conceptual device is introduced which would utilize unsteady wave motion to slow and turn flows in the diffuser section of a centrifugal compressor. The envisioned device would substantially reduce the size of conventional centrifugal diffusers by eliminating the relatively large ninety degree bend needed to turn the flow from the radial/tangential to the axial direction. The bend would be replaced by a wall and the flow would instead exit through a series of rotating ports located on a disk, adjacent to the diffuser hub, and fixed to the impeller shaft. The ports would generate both expansion and compression waves which would rapidly transition from the hub/shroud (axial) direction to the radial/ tangential direction. The waves would in turn induce radial/tangential and axial flow. This paper presents a detailed description of the device. Simplified cycle analysis and performance results are presented which were obtained using a time accurate, quasi-one-dimensional CFD code with models for turning, port flow conditions, and losses due to wall shear stress. The results indicate that a periodic wave system can be established which yields diffuser performance comparable to a conventional diffuser. Discussion concerning feasibility, accuracy, and integration follow.

\begin{tabular}{|c|c|}
\hline 14. SUBJECT TERMS \\
Compressor; Diffuser; CFD \\
$\begin{array}{c}\text { 17. SECURITY CLASSIFICATION } \\
\text { OF REPORT } \\
\text { Unclassified }\end{array}$ & $\begin{array}{c}\text { 18. SECURITY CLASSIFICATION } \\
\text { OF THIS PAGE } \\
\text { Unclassified }\end{array}$ \\
\hline
\end{tabular}

\begin{tabular}{|c|c|}
\hline & $\begin{array}{c}\text { 15. NUMBER OF PAGES } \\
12\end{array}$ \\
\hline & $\begin{array}{r}\text { 16. PRICE CODE } \\
\mathrm{A} 03\end{array}$ \\
\hline $\begin{array}{l}\text { 19. SECURITY CLASSIFICATION } \\
\text { OF ABSTRACT } \\
\text { Unclassified }\end{array}$ & 20. LIMITATION OF ABSTRACT \\
\hline
\end{tabular}

